Mal J Nutr 26(1): 093-099, 2020

SHORT COMMUNICATION

\title{
Nutritional composition of indigenous durian varieties
}

\author{
Parunya Thiyajai ${ }^{1}$, Somsri Charoenkiatkul ${ }^{1}$, Kasem Kulpradit ${ }^{2}$, Sasivimon \\ Swangpol $^{3}$, Piyanut Sridonpai ${ }^{1} \&$ Kunchit Judprasong $^{1^{*}}$ \\ ${ }^{1}$ Institute of Nutrition, Mahidol University, Putthamonthon 4 Rd., Salaya, \\ Phutthamonthon, Nakhon Pathom, 73170 Thailand; ${ }^{2}$ Faculty of Environment \\ and Resource Studies, Mahidol University, Putthamonthon 4 Rd., Salaya, \\ Phutthamonthon, Nakhon Pathom, 73170 Thailand; ${ }^{3}$ Department of Plant Science, \\ Faculty of Science, Mahidol University, Rama VI Road, Ratchathewi District, Bangkok \\ 10400 Thailand
}

\begin{abstract}
Introduction: Data on nutrients of indigenous durians are useful for selecting suitable varieties for future cultivation and conservation. The objective of this study is to investigate the nutrient composition (proximate composition, dietary fibre, minerals, sugars, and fatty acids) of 17 indigenous durian varieties from Thailand. Methods: The edible part of each variety was collected, freeze dried, and kept in a freezer until analysis. All parameters were analysed by International Organization for Standardization (ISO) 17025 accredited laboratories using the Association of Official Analytical Chemists (AOAC) standards or well-validated methods. Results: All varieties of durian contained protein, fat $[2.2-3.4 \mathrm{~g}$ and $2.6-6.1 \mathrm{~g} / 100 \mathrm{~g}$ fresh weight $(\mathrm{FW})$, respectively], and carbohydrate $(20.0-39.5 \mathrm{~g} / 100 \mathrm{~g}$ FW). Sugars were predominantly found (14.2-21.8g/100g FW) and sucrose was the major form of sugars (50.0-90.0\%). For the most part, all varieties contained considerable amounts of potassium, sulphur, and phosphorus. Oleic acid (C18:1n9) was the major monounsaturated fatty acid and palmitic acid (16:0) was the major saturated fatty acid $(27.9-51.9 \%$ and $35.6-48.3 \%$, respectively) in all varieties. Conclusion: Varieties of Kob-wat-kuay, Kob-sao-noi, and Kob-wai provided several beneficial compounds but also had unhealthy nutrients in small amounts. This food composition database information is beneficial for selecting good varieties for the purpose of conservation, healthy consumption, and export promotion.
\end{abstract}

Keywords: Durian, food composition, nutrient, fatty acid

\section{INTRODUCTION}

Durian (Durio zibethinus L.) is wellrecognised as the king of fruits and is widespread among Southeast Asian countries including Thailand. Although durian can grow in various regions of Thailand, the Nonthaburi province, a suburb of Bangkok, is well-known as the best place for growing durian due to its taste and high biodiversity. However, severe flooding in 2011 caused serious damage to many durian orchards. After that, various varieties of indigenous durians have been chosen and grown by

\footnotetext{
*Corresponding author: Dr Kunchit Judprasong Mahidol University, c/o Institute of Nutrition, Mahidol University, Nakhon Pathom, 73170 Thailand Tel: (66)(0)28002380; Fax: (66)(0)24419344; E-mail: kunchit.jud@mahidol.ac.th https://doi.org/10.31246/mjn-2019-0083
} 
durian gardeners in different provinces of Thailand.

Data on nutrients, sugars, fatty acids, and antioxidant activities of indigenous durians are useful for selecting suitable varieties for future cultivation and conservation. However, such information for indigenous durian varieties is limited. A study by Charoenkiatkul et al. (2016) in the Nonthaburi province showed that indigenous durian varieties, such as Chani and Kob-ta-kam, exhibited higher levels of nutrients, bioactive compounds, and antioxidant activities than popular durian varieties, such as Mon-thong and Kra-dum. Data on the nutritive value of popular durian varieties such as Monthong, which is grown in the Rayong and Chantaburi provinces in eastern Thailand have been reported (Haruenkit et al., 2007; Charoensiri et al., 2009; Haruenkit et al., 2010). Ho and Bhat (2015) also presented information about the nutritional composition of popular commercial durian varieties. The Thai and ASEAN Food Composition Database contain information about the most popular and some indigenous durian varieties, but the data are limited and incomplete (Puwastien et al., 2015), especially in terms of proximate composition, as well as some minerals and vitamins. Consequently, 17 varieties of indigenous durian fruits were studied in terms of proximate composition, dietary fibre, minerals, sugars and fatty acid composition.

\section{MATERIALS AND METHODS}

Food sampling and sample preparation 17 varieties of indigenous durians (Durio zibethinus L.) were studied, namely, Baht-thong-kum, Chao-koa, Chom-phusri, Dao-kra-jai, Keng-tong, Kob-mae-tao, Kob-pi-kul, Kob-sao-noi, Kob-ta-khao, Kob-ta-tao, Kob-wai, Kob-wat-kuay, Kum-pun-chao-kom, Kum-pun-nurkhao, Kum-pun-puang, Sao-chom, and
Tong-yoi-chat. The durian fruits were selected and three fruits of each variety were collected by local gardeners in the Nonthaburi province during April to May 2011, before the severe flooding occurred. More than 50 years ago, these indigenous durian varieties were selected to grow in the Nonthaburi province, Thailand. According to local gardeners, the optimum ripeness of the durian fruits were 3-7 days after harvest, depending on the variety, combined with the characteristics of the flesh adhering to the thick shell (Haruenkit et al., 2010). After collection, each durian fruit was transported to the Institute of Nutrition, Mahidol University laboratory. After ripening, each durian was peeled and the edible part was cut into pieces using a plastic knife. Each sample was divided into two portions; first portion used for moisture analysis and the second portion used for freeze drying. For moisture analysis, the durian flesh was homogenised, put in an acid-washed plastic bottle and kept at $-20^{\circ} \mathrm{C}$ until ready for analysis. For the preparation of freeze-dried samples, the pieces of each sample were put into a freeze-drying machine for $36 \mathrm{~h}$ until dried and then homogenised into fine powder. They were packed in vacuumsealed laminated aluminium foil bags and stored at $-20^{\circ} \mathrm{C}$ until analysis.

\section{Nutrient determination}

Standard Association of Official Analytical Chemists (AOAC) methods (AOAC International, 2019) were used for proximate, minerals, sugars and fatty acids analyses. All samples were analysed at the ISO 17025 accredited laboratory, Institute of Nutrition, Mahidol University, which provided international standards for laboratory quality systems. The results of measurements from three composite samples were presented as mean \pm standard deviation $(S D)$ on a fresh weight (FW) basis. 
Proximate composition

Standard AOAC method no. 952.45 (AOAC International, 2019) using hot air oven was used for moisture analysis. Method no. 981.10 (AOAC International, 2019) using the Kjeldahl method was used for total nitrogen analysis, and calculated into protein content using specific (Jones) factors. Method no. 945.16 (AOAC International, 2019) was applied for crude fat analysis by acid digestion prior to continuous extraction using petroleum ether in Soxtec system. Method no. 945.46 (AOAC International, 2019) was used for ash analysis by incinerating all organic matters at $550 \pm 5^{\circ} \mathrm{C}$. Method no. 991.43 (AOAC International, 2019) was applied for total dietary fibre analysis using enzymatic gravimetric method. Available carbohydrate was calculated using the following formula: 100-(moisture+protein+fat+ash+dietary fibre) and energy was calculated by Atwater factor.

\section{Minerals}

Method no. 984.27 (AOAC International, 2019) using acid digestion in a closed Teflon vessel was employed for determining magnesium, iron, copper, and zinc using an inductively coupled plasma optical emission spectrophotometer (ICP-OES). The acid solution was analysed by flame atomic absorption spectrophotometer (AAS) for the determination of calcium, sodium, and potassium using method no. 975.03 (AOAC International, 2019). The acid solution was also determined for phosphorus by gravimetric method (AOAC International, 2019).

\section{Sugars}

Sugars including fructose, glucose and sucrose contents were determined using a high pressure liquid chromatography (HPLC) with evaporative light scattering detector (ELSD), method no. 980.13
(AOAC International, 2019). Sum of all individual sugar was reported as total sugars.

\section{Fatty acids}

After fat extraction, fatty acids were extracted using hydrolytic methods. Extracted fat was dissolved in petroleum ether, then methylated to fatty acid methyl esters (FAMEs) using boron trifluoride in methanol. Fatty acids were separated by capillary columns installed in the gas chromatography (GC) system against $\mathrm{C} 17: 0$ internal standard, method no. 996.06 (AOAC International, 2019).

\section{Quality control of laboratory analysis}

All analytical methods were validated or verified to fulfill the requirement of ISO/IEC 17025 accreditation. Inhouse quality control (QC) samples were prepared and measured for every batch of samples including milk powder (for total nitrogen, moisture and crude fat analyses), and defatted soybean flour (for ash, total dietary fibre, and mineral analyses). The results of QC samples for each batch were within the mean of $\pm 2 S D$ of the assigned values as presented in a previous study (Judprasong et al., 2013). The percent relative standard deviation (RSD) of the assigned values was also no more than 10 .

\section{RESULTS AND DISCUSSION}

\section{Nutrients}

Proximate compositions

The edible portion, energy, proximate compositions, and sugars of the 17 durian varieties are shown in Table 1. Edible portions ranged from $23.5 \pm 2.1 \%$ in the Baht-thong-kum variety to $30.5 \pm 1.3 \%$ in the Kob-ta-tao variety. The major component was water, which was the lowest in the Chao-koa variety $(54.2 \pm 0.1 \mathrm{~g} / 100 \mathrm{~g}$ edible FW) and the highest in the Kob-sao-noi variety (73.3 $\pm 2.3 \mathrm{~g} / 100 \mathrm{~g}$ FW). The durian 


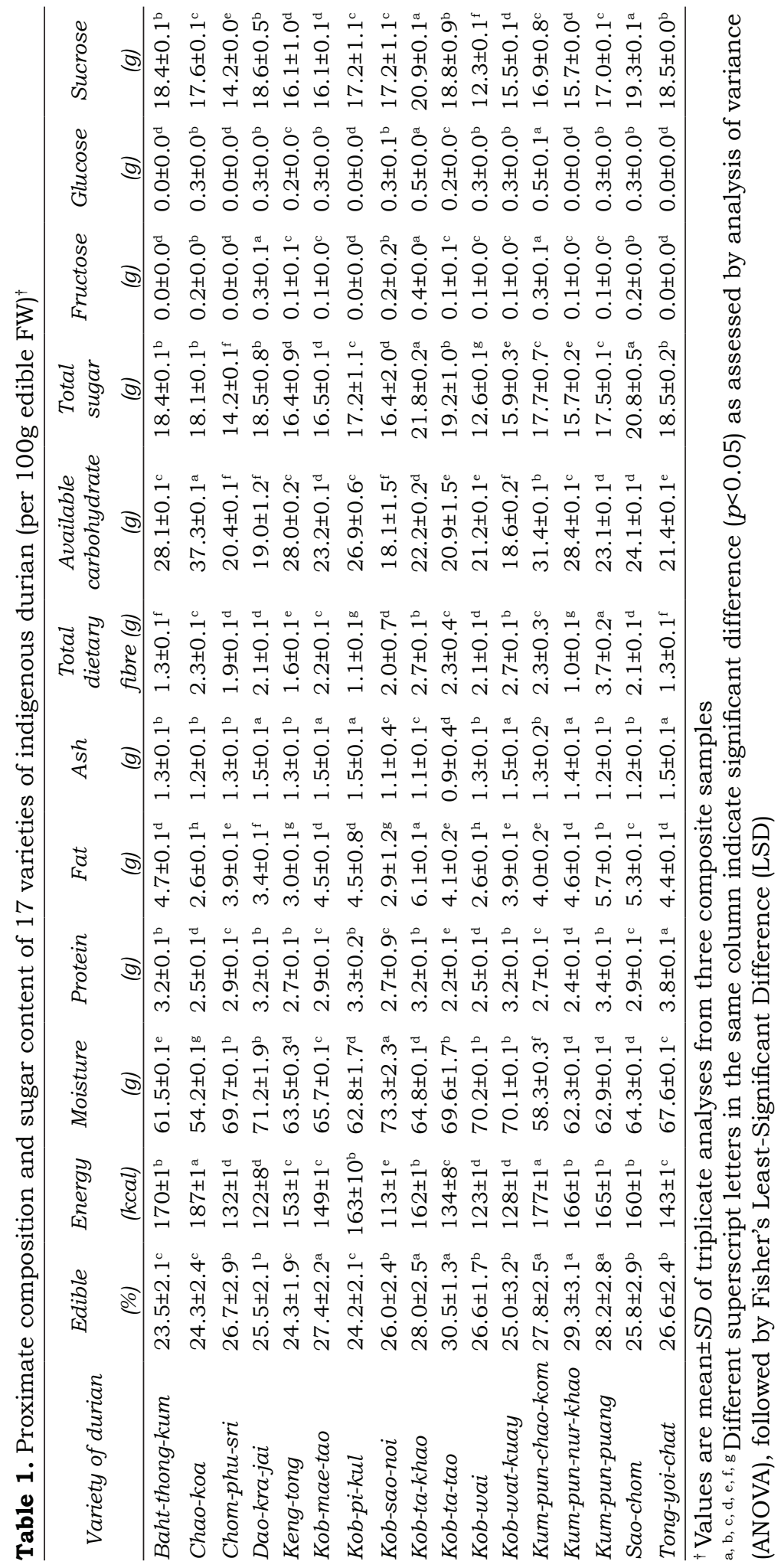




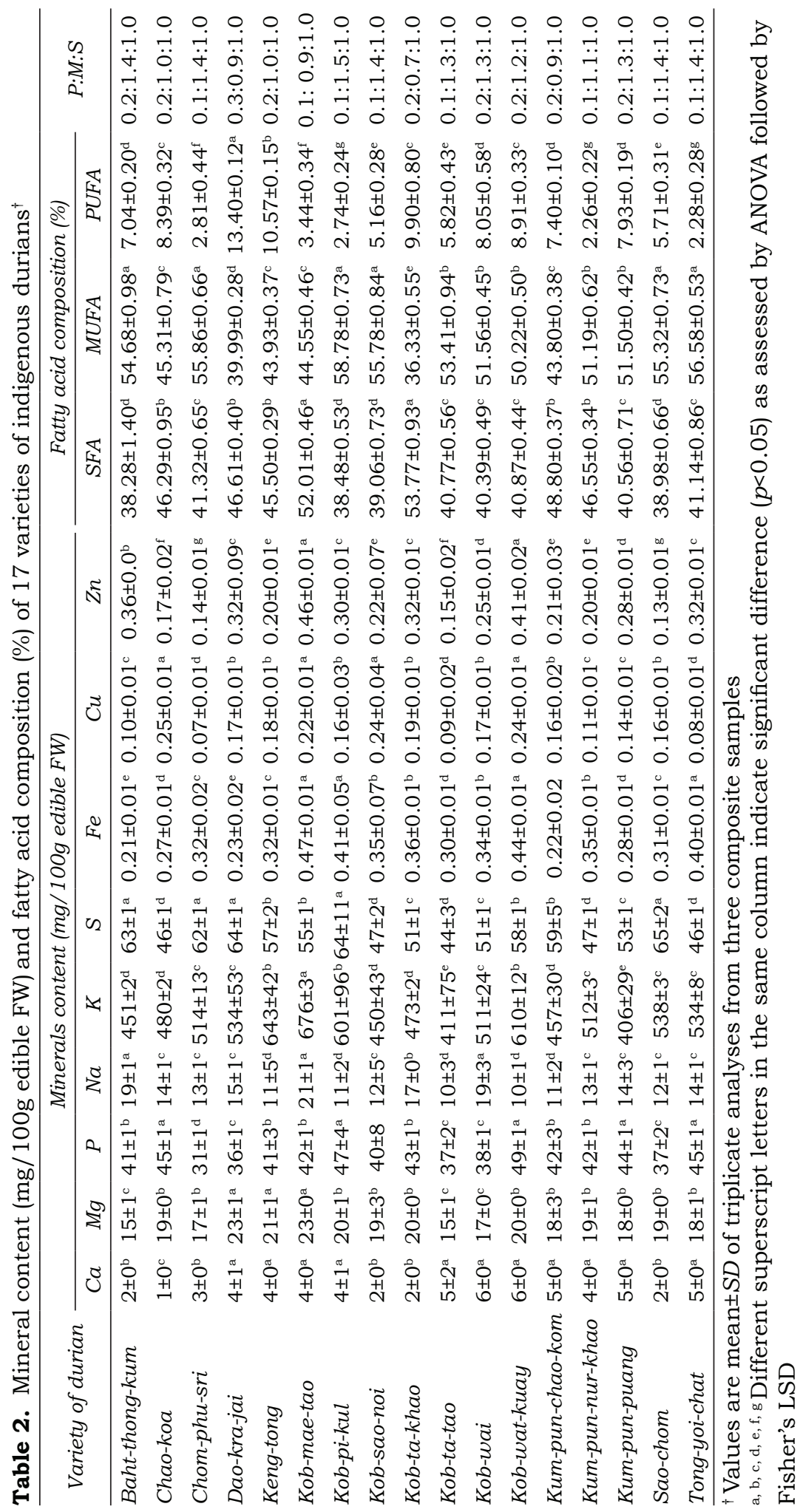


varieties provided a noteworthy amount of protein (2.4-3.8g/100g FW), which was equal to $5.3-10.6 \mathrm{~g} / 100 \mathrm{~g}$ dry weight (dry matter, DM). The protein levels in all varieties were higher than those reported previously with $4.2 \mathrm{~g} / 100 \mathrm{~g}$ DM (Ho \& Bhat, 2015). Fat levels ranged from $2.6 \pm 0.1 \mathrm{~g} / 100 \mathrm{~g} \mathrm{FW}$ (equal to 5.6g/100g DM) in Chao-koa and Kob-wai varieties to $6.1 \pm 0.1 \mathrm{~g} / 100 \mathrm{~g} F W$ (equal to $14.8 \mathrm{~g} / 100 \mathrm{~g} \mathrm{DM}$ ) in the Kob-ta-khao variety. Some durian varieties exhibited the same levels of fat as reported by Ho and Bhat (2015) (15.2g of fat/100g DM). All varieties of durian contained total dietary fibre $(1.0-3.7 \mathrm{~g} / 100 \mathrm{~g} \mathrm{FW}$ equal to $2.5-10.1 \mathrm{~g} / 100 \mathrm{~g} \mathrm{DM})$, which was similar to previous reports $(3.4 \mathrm{~g} / 100 \mathrm{~g}$ and $9.1 \mathrm{~g} / 100 \mathrm{~g}$ DM, respectively) (Haruenkit et al., 2007; Gorinstein et al., 2011). The durian varieties also contained various amounts of available carbohydrates (18.1-37.3g/100g FW, equal to $63.3-81.8 \mathrm{~g} / 100 \mathrm{~g} \mathrm{DM})$ and total sugars $(14.2-21.8 \mathrm{~g} / 100 \mathrm{~g} F W$, equal to $38.8-67.5 \mathrm{~g} / 100 \mathrm{~g} \mathrm{DM})$. Almost all of the sugars were found to be sucrose (92.7$100.0 \%)$.

\section{Minerals}

Of all the studied macro and trace elements [calcium (Ca), magnesium $(\mathrm{Mg})$, phosphorus $(\mathrm{P})$, sodium $(\mathrm{Na})$, potassium $(\mathrm{K})$, sulphur $(\mathrm{S})$, iron $(\mathrm{Fe})$, zinc $(\mathrm{Zn})$, and copper $(\mathrm{Cu})], \mathrm{K}$ was the highest in amount, ranging from 406-676mg/100g FW (Table 2), which is equal to $1010-1895 \mathrm{mg} / 100 \mathrm{~g} \mathrm{DM}$. This range was close to that reported by Dembitsky et al. (2011) (1245mg/100g $\mathrm{DM})$, and higher than that reported by Haruenkit et al. (2007) (574mg/100g $\mathrm{DM})$. All durian varieties also contained $\mathrm{S}, \mathrm{P}, \mathrm{Mg}$, and $\mathrm{Na}$ (44-65, 31-49, 15-23, and $10-21 \mathrm{mg} / 100 \mathrm{~g}$ FW, respectively), but they contained very low amount of calcium (1-6 mg/100g FM). These findings were in the same range as those reported in previous studies (Haruenkit et al., 2007; Dembitsky et al., 2011). For trace elements, all durian varieties contained $\mathrm{Fe}, \mathrm{Cu}$, and $\mathrm{Zn} \mathrm{(0.21-0.47,}$ $0.08-0.25$, and $0.13-0.46 \mathrm{mg} / 100 \mathrm{~g}$ $\mathrm{FM}$, respectively) in the same range as previous reports (Haruenkit et al., 2007; Dembitsky et al., 2011).

\section{Fatty acids}

Data on the sum of saturated fatty acid (SFA), monounsaturated fatty acid (MUFA) and polyunsaturated fatty acid (PUFA) composition for all durian varieties are also presented in Table 2. Oleic acid (C18:1n9) was the major MUFA and palmitic acid (16:0) was the major SFA (27.91-51.88\% and 35.63$48.27 \%$ of total fatty acids, respectively) in all varieties, which agreed well with a previous study (Haruenkit et al., 2010). Most of the indigenous varieties, except for six varieties (i.e. Chao-koa, Dao-kra-jai, Keng-tong, Kob-mae-tao, Kob-ta-khao and Kum-pun-chao-kom) contained MUFA $>$ SFA $>$ PUFA (50.22$58.78 \%, 38.28-41.32 \%, 2.26-8.91 \%$ of total fatty acids, respectively). The ratio of PUFA:MUFA:SFA (P:M:S ratio) in these varieties was $0.1-0.2: 1.1-1.4: 1.0$. The P:M:S ratio in this group agreed well with the ratio reported by the MOPH Thailand (2002), which was 0.3:1.4:1.0.

\section{CONCLUSION}

17 indigenous durian varieties from the orchards of Nonthaburi province, Thailand, were compared in terms of their diversity in nutrients and fatty acid composition. Each durian variety has its unique health benefit depending upon its composition. Among the 17 varieties from this study, Kob-wat-kuay, Kobsao-noi, Kob-wai, Kob-pi-kul and Kumpun-puang varieties provided several beneficial nutrients. All durian varieties contained high sugar and carbohydrate levels and should be consumed in limited amounts on a daily basis. The 
nutrient composition data of these durian varieties can be used to update the Thai and ASEAN food composition databases. They can also be used for selecting optimal durian varieties for the purpose of cultivation, conservation, healthy consumption, and exportation promotion.

\section{Acknowledgement}

The Biodiversity-Based Economy Development Office (BEDO) and National Research Council of Thailand supported this research (funded code $15 / 2015)$ for which we are grateful. We would also like to thank Mr. George A. Attig and Ms. Christine Stanly for editorial assistance.

\section{Authors' contributions}

PT, prepared samples at laboratory, conducted data collection and analysis; SC, advised on the conceptualisation and designed the study; KK, conducted preparation and sample collection at studied areas; SS, conducted preparation and sample collection at studied areas; PS, conducted preparation and sample collection at laboratory, and conducted data collection; KJ, principal investigator, conceptualised and designed the study, collected samples at studied areas and prepared samples at laboratory, prepared the draft of the manuscript and reviewed the manuscript.

\section{Conflict of interest}

All authors declared that there is no conflict of interest in this study.

\section{References}

AOAC International (2019). Official Methods of Analysis of AOAC International. 21th Edition. George WL (ed). Association of Official Analytical Chemists International, Rockville, MD.

Charoenkiatkul S, Thiyajai P \& Judprasong K (2016). Nutrients and bioactive compounds in popular and indigenous durian (Durio ziberhinus L.). Food Chem 193:181-186.

Charoensiri R, Kongkachuichai R, Suknicom S \& Sungpuag P (2009). Beta-carotene, lycopene, and alpha-tocopherol contents of selected Thai fruits. Food Chem 113:202-207.

Dembitsky VM, Poovarodom S, Leontowicz H, Leontowicz M, Vearasilp S, Trakhtenberg S \& Gorinstein S (2011). The multiple nutrition properties of some exotic fruits: Biological activity and active metabolites. Food Res Int 44:1671-1701.
Haruenkit R, Poovarodom S, Leontowicz H, Leontowicz M, Sajewicz M, Kowalska T, Delgado-Licon E, Rocha-Guzmán NE, GallegosInfante JA, Trakhtenberg S \& Gorinstein S (2007). Comparative study of health properties and nutritional value of durian, mangosteen, and snake fruit: experiments in vitro and in vivo. J Agr Food Chem 55(14):5842-9.

Haruenkit R, Poovarodom S, Vearasilp S, Namiesnik J, Sliwka-Kaszynska M, Park Y, Heo B, Cho J, Jang H \& Gorinstein S (2010). Comparison of bioactive compounds, antioxidant and antiproliferative activities of Mon Thong durian during ripening. Food Chem 118:540-547.

Ho L \& Bhat R (2015). Exploring the potential nutraceutical values of durian (Durio zibethinus L.) - An exotic tropical fruit. Food Chem 168:8089.

Judprasong K, Charoenkiatkul S, Thiyajai P \& Sukprasansap M (2013). Nutrients and bioactive compounds of Thai indigenous fruits. Food Chem 140:507-512.

MOPH Thailand (2002). Fatty Acids and Cholesterol in Thai Foods. Bureau of Nutrition, Ministry of Public Health Thailand.

Puwastien P, Judprasong K, Sridonpai P \& Saiwan $\mathrm{T}$ (2015). Thai Food Composition Tables 2015. Second edition. Institute of Nutrition, Mahidol University, Thailand. 